\title{
Oral Polio Vaccine: Misconceptions, Challenges And The Way Forward For Nigeria.
}

\author{
Maigari, B. ${ }^{\text {a }}$, Muhammad, R. ${ }^{b}, \mathrm{Habu}, \mathrm{H}^{\mathrm{c}}$ \\ ${ }^{a}$ Department of Nursing Science, University of Maiduguri. \\ ${ }^{b}$ Department of Nursing Science, University of Maiduguri. \\ ${ }^{c}$ Department of Nursing Science, University of Maiduguri.
}

\begin{abstract}
Polio vaccine is targeted towards preventing poliomyelitis; a condition characterized by inflammation of the spinal cord and neighboring structures resulting to paralysis of the limbs and organs and possibly becoming handicapped for life. Nigeria is one of the three countries where poliomyelitis is still endemic (WHO, 2009). As part of the immunization schedule in Nigeria towards the fight against the menace, 2 to 3 drops of oral polio vaccines are administered orally at certain intervals to any child within the range of 0-5 years. Challenges which comprises of misconceptions about polio vaccine, political and religion factors coupled with insecurity among others constitute a serious challenge as far as polio eradication in Nigeria is concern. Misinformation and controversy surrounding polio campaign should be squarely addressed through robust public enlightenment campaign. Implementation of communication intervention based on routine monitoring of epidemiological, social and behavioural data on affected population, enacting of workable laws, on polio immunization, availability of functional health facilities coupled with adequate manpower and involvement of community leaders are some of the way forward for Nigeria in eradicating poliomyelitis.
\end{abstract}

Key words: Oral polio vaccine, Misconceptions, Challenges.

\section{Introduction}

Nigeria's population is well over 160 million with children below the age of 5 years making up $44 \%$ (National population census, 2006; world population prospects, 2012) from which about $22 \%$ of child mortality are due to vaccine preventable diseases (USAIDS,2004; 2009). According to UNICEF (2004); between 2001 and 2003, many states in the Southern part of Nigeria were declared polio free and were subsequently reinfected by cases from the Northern part of the country. There is a geographical disparity in incidence rates of polio across the Nigerian state, and it is split between the Southern predominantly Christian population and the Northern predominantly Muslim population (Renne, 2010; Oluwadare, 2009). This disparity is so evident that the available literatures only discuss polio in Northern Nigeria and label the South as polio free as explained by Samba, Nkrumah and Leke (2004), even though this title is short lived because of the problem of re-infection. This disparity exists, not only in the rate of disease incidence, but also the utilization of globally recommended and accepted preventive care: immunization (Renne, 2010). For years, polio vaccination has faced strong resistance within conservative Islamic communities as explained by Integrated Regional Information Network (2013) adding that it is largely due to the distrust Northern Nigeria has for the west, persistent rumors that the vaccine is harmful and the house-to-house approach taken by immunization campaigners is too intrusive. Confirming the above, Adepitan (2013) affirms that in 2011, more than 95\% of all new cases occurred in Borno, Jigawa, Kano, Katsina, Kebbi, Sokoto, Yobe and Zamfara, the eight Northern states where the disease is endemic, where the un-enlightened people claim that polio vaccine contains birth control drugs as part of a secret plot to reduce the population growth in the Muslim world by the west.

Polio vaccine is targeted towards preventing poliomyelitis; a condition characterized by inflammation of the spinal cord and neighboring structures resulting to paralysis of the limbs and organs and possibly becoming handicapped for life. As part of the immunization schedule in Nigeria, 2 to 3 drops of oral polio vaccines are administered orally at certain intervals to any child within the range of $0-5$ years. This is aimed at helping to prevent the child from contracting poliomyelitis which has a devastating effect.

Despite all the effort by the federal government of Nigeria at achieving a polio free nation; Kano state in 2004 boycotted polio immunizations for 11 months, 10 vaccinators were killed in Kano state and 2 in Dikwa, Borno state in 2013, with fresh cases of wild polio virus still reported in the North east region of the country. Therefore, the federal government and several stakeholders have tried to examine the problems, challenges and misconceptions about the vaccine in other to proffer lasting solutions at eradicating the virus completely from Nigeria with support from non-governmental organizations and international agencies. 


\section{Misconceptions about Immunizations and Vaccines}

Poliomyelitis was first recognized as a distinct condition by Jakob Heine in 1840. Its causative agent poliovirus was identified in 1908 by Karl Landsteiner (Paul, 1971). Major epidemics of polio according to Trevelyan, Smallman-Raynor and Cliff (2005), started to appear in the late $19^{\text {th }}$ century in Europe and soon after the United States and it became one of the dreaded childhood diseases of the $20^{\text {th }}$ century. Poliomyelitis, polio or infantile paralysis is caused by the poliovirus, a member of the family picornaviridae. The poliovirus is a naked, positive-strand RNA virus with three different serotypes (Nwozor, 2013).

The oral polio vaccine (OPV) developed against the menace of poliomyelitis is also called "trivalent oral polio vaccine" or "Sabin vaccine". OPV consists of a mixture of live attenuated (weakened) poliovirus strains of all three polio virus types. OPV produces antibodies in the blood to all three types of poliovirus

Nigeria's Expanded Programme on Immunization (EPI) was first initiated in 1979 and the federal government of Nigeria through the federal ministry of health continues to place high priority on immunization. In 1999, a new drive to sustainably re-vitalize the immunization system commenced in synergy with the accelerated strategy on polio eradication. Consequently, the federal government established the national programme on immunization (NPI) whose key focus was to provide support to the implementation of state and local government area (LGA) immunization programmes (WHO, 2009).

Misconceptions about polio vaccine have remained a strong barrier in eliminating the disease globally. Some of these misconceptions include, cases which had previously been reported as polio are now reported as meningitis and the risk of contracting polio from the live virus vaccine is greater than the risk of acquiring the disease from naturally occurring viruses (Kent and Gentempo, 2000).

As adapted from the college of physicians of Philadelphia (2014), many misconceptions about vaccines have persisted for decades because of a poor understanding of how vaccination works. Some of the most common vaccination related misconceptions are addressed here.

- The "Overloaded Immune System" Misconception

Perhaps the most common misconception is that a child's immune system can be "overloaded" if the child receives multiple vaccines at once. This concern first began to appear as the recommended immunization schedule expanded to include more vaccines and as some vaccines were combined into a single shot. However studies have repeatedly demonstrated that the recommended vaccines are no more likely to cause adverse effects when given in combination than when they are administered separately.

Some parents decide to "spread out" the time period during which their children receive vaccination "just in case" this misconception is accurate. However, there is no scientific evidence to support this approach, and delaying vaccinations put children at risk of contracting preventable diseases.

- The "Disappeared Disease" Misconception

Some people assume that because diseases like polio have disappeared from the United States, it's no longer necessary to vaccinate children against them. However, polio is still widespread in other parts of the world and could easily begin to re-infect unprotected individuals if re-introduced to the country. Another example is measles, which has become rare in the United States: U.S outbreaks of the disease have occurred when Americans travelling to countries where measles remain widespread brought the disease back with them. With adequate vaccination rates, most of these types of outbreaks can be prevented. But if vaccination rates drop, "imported" cases of preventable diseases can begin to spread again.

- The "more vaccinated than unvaccinated people get sick" misconception

During an outbreak, the number of vaccinated individuals who get sick will often outnumber the unvaccinated people who get sick. This; however, is not true because vaccines are ineffective.

- The "hygiene and better nutrition are responsible for the reduction in disease rate not vaccination" misconception

Improved hygiene and nutrition among other factors can certainly lower the incidence of some diseases. Data documenting the number of cases of a disease before and after the introduction of a vaccine however, demonstrate that vaccines are overwhelmingly responsible for the largest drops in disease rates.

- The "natural immunity is better than vaccine-acquired immunity" misconception

Some people argue that the immunity gained from surviving a natural infection provides better protection than that provided by vaccines. While it's true that natural immunity lasts longer in some cases than vaccine-induced immunity can, the risks of natural infection outweighs the risks of immunization for every recommended vaccine.

The benefits of vaccine-acquired immunity extraordinarily outweigh the serious risks of natural infection even in cases where boosters are required to maintain immunity.

- Rumors On The Vaccine

The chilling legacy of the live polio vaccine may be the virus associated with AIDS. In his book titled "The River: A Journey to the Source of HIV and AIDS" Hooper, E. suggested that AIDS may be the result of a live virus polio vaccine administered in Africa in the 1950s. According to him, the vaccine may have been 
contaminated with a simian (monkey) virus (Hooper, 1999). This virus is thought to have evolved into the HIV virus. Although the theory is controversial, it demonstrates how the potential risk of vaccines may not become evident until decades after their administration.

\section{Misconceptions in Northern Nigeria}

Nigeria, as indicated earlier is one of the three countries where poliomyelitis is still endemic (WHO, 2009) however; in Northern Nigeria in 2003, the political and religious leaders of Kano, Zamfara, and Kaduna states brought the immunization campaign to a halt by calling on parents not to allow their children to be immunized. These leaders argued that the vaccine was contaminated with anti-infertility agents (estradiol hormone), HIV and cancerous agents (Jegede, 2007). In some communities in Northern Nigeria, it is believed that polio is due to an evil spirit that drinks the blood of its victims leading to paralysis or death (Renne, 2010).

Many Muslims in the north believed that polio vaccination is being used as a plot by western countries to inject people with certain chemicals to reduce their fertility or infect them with HIV/AIDS in order to reduce the population of the Muslims. This came after the boycott and the federal government thus sent a high powered team to investigate the safety of the vaccine and until then the polio immunizations were suspended (IRIN, 2004). The three states involved; Kano, Zamfara and Kaduna gave into rumor sand suspicions going back several years which had culminated in the widespread rejection of polio vaccinations in the North. Tests carried out in two separate countries; Nigeria and South Africa came back negative however Kano state conducted its own separate test and indicated the presence of a hormone-estrogen which is capable of lowering fertility in women. In the meantime, polio, which had been eradicated in almost all of Nigeria with the exception of Kano state-the last known reservoir - has made a comeback. Not only in Nigeria, but also in several neighboring countries where it had previously been wiped out (IRIN, 2004). In the year 2012, the country had recorded 122 cases, about half of the global estimates of polio (IRIN, 2013). Some of the major assumptions are categorized thus:

\section{Geo-Politics}

The major reason why people reject polio vaccine is the deep-seated suspicion they harbor against the west, particularly the United States due to its foreign policies in the Muslim world, especially the war in Iraq and Afghanistan as explained by Sheikh Nasir Muhammad Nasir, Imam of Fagge Juma'at mosque who is an advocate on polio immunization. He, Nasir Muhammad Nasir added that "the US invasion of Iraq and Afghanistan, which caused death and destruction, is seen by many Muslims as a war against their brethren. They wonder how the same countries responsible for this colossal carnage can now turn and save lives elsewhere. And thus, Polio vaccination exercise has been facing strong resistance in the communities of Northern Nigeria, largely because of mistrust to the Western ideas.

\section{Infertility}

There are persistent rumors that the vaccines make children barren when they have grown into adult. Again IRIN (2013) reported that there were a lot of suspicions that the polio vaccines are laced with infertility hormones as part of the US-led plot to reduce the Muslim population.

The Kano state government suspended polio immunizations between September 2003 and November 2004 following the spread of such rumors by some Muslim clerics. The suspension led to an unprecedented number of infections and transmissions of the virus.

In an effort to tackle the issue, Kano state government and the federal government set up committees of medical expert and religious cleric to verify and substantiate the rumors against polio vaccine. The committees were able to establish among other things traces of sex hormones-estrogen and progesterone-used in contraceptive, something that re-enforced the sterility rumor in some communities. The vaccine was said to have contained parts of vital organs from monkey as essential ingredients, which carry traces of two hormones. It is believed that since hormones are water soluble, the traces are bound to be found in the vaccine. A professor of medicine Dr. Sadiq Wali, who served in the committee, said the amounts of the so called hormones are very small and negligible that will not affect human fertility to those who were immunized (IRIN, 2013).

\section{Lingering Anti-Colonial Sentiments}

Much of the long standing distrust of the western influence among Northern Nigerians can be linked to the British Colonial occupation and its dealings with the Islamic caliphates. Another major incidence which further hampered immunization activities was the Pfizer meningitis trial where the US pharmaceutical manufacturer conducted a trial on the meningitis drug Trovan (trovafloxacin) on 200 children at the state-run infectious diseases hospital (IDH) in Kano. At the time, a triple epidemic of meningitis, measles and cholera in the city had killed around 12,000 people. One hundred children were put on Trovan and 100 on the antibiotic ceftriaxone. Eleven children that participated in the trial died, and others suffered paralysis, brain damage and slurred speech. Pfizer claimed it was meningitis that had made the affected children sick. The families alleged the 
clinical trial was improperly conducted and lacked parental consent. The Pfizer drug trial was a real setback against not only polio vaccination but to other child health interventions in the north, because it destroyed public confidence and made the anti-polio campaign readily believable.

\section{Changing Approaches}

Early polio campaigner's approaches were also seen as too insistent, combining radio advertisements, community workshops and teams of health workers going door to door (IRIN, 2013). The house-to-house approach taken by immunization campaigners is also seen as intrusive. Most inoculations take place in health clinics or hospitals many families did not trust health workers arriving at their doorstep. Polio campaigners in recent years have since changed their tactics of winning over parents and religious leaders whom are not ready to allow their wards being immunized. Before 2005 , polio campaigners partnered only with political and health authorities. They later learned to work closely with community and religious leaders. Most Northern states have since formed polio immunization task force with village and religious leaders as members. The results were largely positive, with greater community acceptance and an improved understanding of polio and the vaccine. It was reported from an anonymous polio expert, that uptake of the vaccine had increased since 2005 .

But with the recent killing incident of 10 polio vaccination workers in Kano-the approach once again changed. Polio campaign has now been restricted to health clinics and hospitals in some areas during routine immunization exercise and the exercises are entirely being conducted under the administration of government officials. Some medical expert feared that the new approach will undermine government's effort to eradicate polio out of the country. Vaccine workers have to reach at least $90 \%$ of children each receiving four doses over a 6-12months period, according to the World Health Organization and the National Primary Health Care Development Agency (NPHCDA), a body responsible for overseeing polio immunization exercise in Nigeria that have been sensitizing Muslim clerics and traditional title holders in an effort to dispel the misconceptions on vaccine.

As some community areas continue to live in abject poverty and lack portable water, health care facilities as well as electricity supply, a door to door polio campaign may wrongly be perceived and unless sensitizations and efforts to improve standard of living, the target of eradicating polio in Nigeria can hardly be achieved (IRIN, 2013).

\section{Challenges}

A lot of challenges have been encountered in the fight against poliomyelitis: logistical barriers especially in conflict areas, management challenges, uncertain funding, waning political will, persisting anti-vaccine rumors and resistance, silent infections-healthy carriers who spread disease, and cases of vaccine-induced polio (Larson and Ghinai 2011).

Political and religious factors have played significant role in undermining Nigeria's effort at polio eradication especially in the Northern part of the country.

Nigerian strains of the virus spread to 15 other countries (CDC, 2009) many of which have been certified poliofree and were detected as far away as Indonesia (Larson and Ghinai, 2011). It accounted for $80 \%$ of the world's paralytic cases and the financial burden on the international community amounted to more than $\$ 500$ million (WHO, Global Alert and Response 2009).

Misconceptions about oral polio vaccine (OPV) and suspicions about motives behind the campaign emerged, especially in the light of other visible problems (i.e. understaffed clinics, poor roads, other diseases). Misconceptions included: OPV caused illness in children, was ineffective, caused infertility and was part of a plan to curb the growth of Muslim population (UNICEF, 2004). Caregivers reported being tired of repeated rounds and questioned the OPV's efficacy, a situation exacerbated by news coverage accusing the initiative of using a substandard vaccine (Cheng, 2004).

The violent activities of the radical Islamic sect, Boko Haram, have compounded an already complex situation in Nigeria. They have created a climate of fear and insecurity in some parts of Northern Nigeria. The group has been carrying out attacks on government offices, churches, mosques, schools and civilians in parts of the North east significantly affecting regional security and creating regional accessibility challenges for health workers attempting to vaccinate (Nwozor, 2013). In fact; recently, the attack has become worst in North-eastern Nigeria that people especially in the rural areas are after their lives not poliomyelitis.

It is clear that resistance to polio eradication in Nigeria stems principally from misinformation fuelled by local political community and religious leaders. This must be addressed squarely for us to gain momentum and get Nigeria rid of polio. The federal, state governments and other stakeholders must see the eradication of polio as a public health emergency (Nwozor, 2013). 


\section{The Way Forward for Nigeria}

Health care providers are trained to have the best interest of the patients/client's at heart. It is imperative that they work with other stakeholders in health facilities and communities as a whole in ensuring a polio free society. Polio eradication is a multidisciplinary approach and must include the religious and community leaders so as to bring a stop to its persistence. According to Obregon, R., Chitnis, K., Morry, C., Feek, W., Bates, J., Galeway, M., and Oyden, E. (2009) there are lessons to be learnt from countries that have successfully eradicated polio. These include:

1. Implementation of communication intervention based on routine monitoring of epidemiological, social and behavioral data on affected populations.

2. Intensive use of interpersonal communication and social mobilization at different levels to maximize reach, effectiveness and efficiency.

3. Mobilization of community leaders, communication and leadership building, engaging families and care-givers who question repeated polio vaccination.

4. Involving religious leaders as spokespersons and using faith based folk media (i.e. mosques announcements) to reach community members.

5. Working with trained communication outreach workers as part of a house-to-house strategy to reach children missed during national immunization days.

6. Advocacy with intensive grassroots mobilization to reach and communicate with marginalized communities.

7. Addressing social/gender norms to improve interpersonal communication and increasing access to hard-to-reach groups.

More so, Nwozor (2013) stressed that strategic and synergistic communication efforts that integrate social mobilization, interpersonal communication, gender and culturally sensitive interventions, mass media and political advocacy are essential.

In addition to Obregon etal's solutions to eradicate poliomyelitis, the following among others should be observed in ensuring polio eradication in Nigeria:

- Nigerian legislators should pass into law the mandatory immunization of children, polio inclusive. Example can be seen from Niger state, where polio immunization has been passed into law. This means, it is a most that every child in Niger state must be immunized against polio.

- The routine National Immunization schedule should be adhered to strictly. This with the view to ensure full capture of children to avoid non compliance from some parents that do complain of too much rounds of polio immunization thereby refusing their children been immunized after the usual or routine immunization for children.

- Government should ensure the availability of functional health facilities at strategic locations in the Nigerian communities especially at the rural areas with adequate manpower.

- Nigerian government should intensify her effort in providing the necessary amenities for her citizens such as security, water supply, electricity, food through boosting of agriculture, health care services so that people will gladly and readily accept other interventions such as polio immunization.

\section{Summary/Conclusion}

Poliomyelitis remain a serious problem in a large part of the developing world where the disease presents a constant threat to childhood populations with important consequences for social and economic development, (Lucas and Gilles, 1984). This condition is still very prevalent in most Northern states in Nigeria where many families live in abject poverty with high illiteracy rate and poor utilization of health care facilities and its services remain a serious problem in eradicating poliomyelitis. In addition, misconceptions about polio vaccine, political and religion factors coupled with insecurity among others constitute a serious challenge as far as polio eradication in Nigeria is concern. Misinformation and controversy surrounding polio campaign should be squarely addressed through robust public enlightenment campaign. Implementation of communication intervention based on routine monitoring of epidemiological, social and behavioural data on affected population, enacting of workable laws on polio immunization are some of the way forward for Nigeria in eradicating poliomyelitis. The country had witnessed a 95\% decline in the number of polio cases in 2010 and was so close to the finish line with regard to polio eradication. However, as at July 11, 2012, Nigeria has recorded 54 new cases of wild poliovirus in 10 states compared to 25 cases during the same period in 2011 (FMOH, 2012). In 2012, the country declared polio eradication a national emergency. According to a recent report by the chairman of the committee on polio eradication in Nigeria Dr Halliru Alhassan, a total of 43 polio cases was recorded last year (2013) and only 6 polio cases was confirmed this year in Kano and Yobe state. The Nigerian government based on the current number of polio cases and the compliance of her citizens through involvement of community and religious leaders have targeted this year (2014) as her year of break through. In other words, Nigeria shall eradicate poliomyelitis among her populace in the next few months. I believe that unless the 
Nigerian government continues to take proactive measures that comprise the suggestions in this paper and other proactive measures that were not mentioned in the paper; the target of polio eradication in the next few months will continue to be a dream, indeed a mirage.

\section{References}

[1]. Centers for Disease Control and Prevention (CDC), (2009). Morb. Mortal.Weekly Report. 58, 357-362.

[2]. Cheng, W. (2004). Reaching the Unreached: Communication Support for the Pakistan Polio Eradication Initiative. New Delhi: United Nations Children's Fund Regional Office for South Asia.

[3]. Federal Ministry of Health (FMOH) Report, 2012. Abuja, Nigeria.

[4]. Global Polio Eradication Initiative (GPEI), (2011). Polio Eradication This Week. Retrieved from http://www.polioeradication.org

[5]. Hooper, E. (1999) The River: A journey to the source of HIV and AIDS. New York. Little, Brown and company.

[6]. IRIN Africa/analysis: Roots of polio vaccine suspension. Retrieve from www.irinnews.org/report/97781/analysis-roots-of-poliovaccines-suspension. 2004.

[7]. IRIN Africa/analysis: Roots of polio vaccine suspension. Retrieve from www.irinnews.org/report/97781/analysis-roots-of-poliovaccines-suspension. 2013.

[8]. Jegede, A.S. (2007). What Led to the Nigerian Boycott of the Polio Vaccination Campaign? Plosmed 4(3):e73.doi:10.1371/journal.pmed.0040073.

[9]. Kent, C. and Gentempo, P. (2000). "Immunizations: fact, myth, and speculation." International Review of Chiropractic.

[10]. Larson, H.J. and Ghinai I. (2011).Lessons from Polio Eradication. Nature 473:446-447.

[11]. Lucas, A.O and Gilles H.M., (1984) A New Short Textbook of Preventive Medicine for the Tropics. Hodder and Stoughton. London.

[12]. National population census (2006) national population commission, Abuja. Nigeria.

[13]. Nwozor C.M (2013). Facing the challenges of polio eradication in nigeria, Journal of medical and applied biosciences, vol 5, no 1, p100-6

[14]. Obregon, R., Chitnis, K., Morry, C., Feek, W., Bates, J., Galeway, M. and Oyden, E. (2009). Achieving Polio Eradication: A review of health communication evidence and lessons learned in India and Pakistan. Bulletin of the world health organization 87: 624-630.

[15]. Oluwadare, C. (2009). The Social Determinants Of Routine Immunization In Ekiti State Of Nigeria. Studies on Ethno-Medicine. 3()(1):49-56

[16]. Paul, J.R. (1971). A History of Poliomyelitis.Yale Studies in the History of Science and Medicine. New Haven Conn. Yale University Press.

[17]. Population division of the department of economic and social affairs of the United Nations secretariat, world population prospects: the 2012 revision.

[18]. Renne, E. (2010). The Politics of Polio in Northern Nigeria. SocSci. India. Indiana University Press.

[19]. Samba E, Nkrumah F, Leke R, (2004). Getting Polio Eradication Back On Track in Nigeria.NEnglJ Med. 63(7):645-6

[20]. The college of physician of Philadelphia (2014). The history of vaccines. Philadelphia.

[21]. The guardian. Adepitan, A: Nigeria polio drive has been hit by mistrust of 'white medicine'. Monday 19 th august 2013.

[22]. Trevelyan, B., Smallman-Raynor, M. and Cliff, A. (2005). "The Spatial Dynamics Of Poliomyelitis In The United States: From Epidemic Emergence to Vaccine-Induced Retreat, 1910-1971” Ann Assoc Am George 75(2):269-93.

[23]. United Nations Children's Fund (UNICEF) Regional Office for South Asia (2004). Building Trust in Immunization; Partnering with Religious Leaders and Groups (Working Paper). New Delhi.

[24]. USAIDS immunization basic report 2004 and 2009.

[25]. WHO (2009). The World Health Report. World Health Organization, Geneva.

[26]. WHO Global Alert Response, (2009).Poliomyelitis in Nigeria and West Africa, Retrieved from http://www.who.int/csr/don/2009_01_06/en/index.html. 